Research Article

\title{
Physiological Responses and Proteomic Analysis on the Cold Stress Responses of Annual Pitaya (Hylocereus spp.) Branches
}

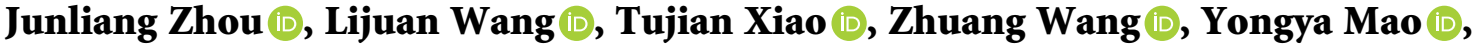 \\ and Yuhua Ma
}

Guizhou Fruit Institute, Guizhou Academy of Agricultural Sciences, Guiyang 550006, China

Correspondence should be addressed to Yuhua Ma; m_yh79@163.com

Received 17 October 2021; Revised 28 October 2021; Accepted 30 October 2021; Published 22 November 2021

Academic Editor: Wenneng Wu

Copyright ( $\odot 2021$ Junliang Zhou et al. This is an open access article distributed under the Creative Commons Attribution License, which permits unrestricted use, distribution, and reproduction in any medium, provided the original work is properly cited.

\begin{abstract}
In this study, the physiological response of the annual branches of three varieties of pitaya (Xianmi, Fulong, and Zihonglong) in cold stress was investigated using a multivariate statistical method. Physiological change results showed that cold stress could decrease the moisture and chlorophyll contents, on the contrary, increase the relative electric conductivity, the contents of malonadehyde, soluble protein, soluble sugar, and free proline, and enhance the enzyme activities of peroxidase, superoxide dismutase, and catalase. Meanwhile, a comparative proteomic approach was also conducted to clarify the cold resistance-related proteins and pathways in annual pitaya branches. Proteomics results concluded that the cold tolerance of annual pitaya branches could be improved by modulating autophagy. Therefore, we hypothesized that an increased autophagy ability may be an important characteristic of the annual pitaya branches in response to cold stress conditions. Our results provide a good understanding of the physiological responses and molecular mechanisms of the annual pitaya branches in response to cold stress.
\end{abstract}

\section{Introduction}

Pitaya (Hylocereus spp.), a member of the family Cactaceae, is a perennial climbing cactus plant which is rich in anthocyanins, betanin, and plant albumin $[1,2]$. Because of the ability of pitaya to resist prolonged drought, it is considered to have a high potential for agricultural development, especially in the drought areas [3,4]. Therefore, pitaya has been a thriving fruit and large-scale commercial cultivation in the karst regions of southwest China, such as Guangxi, Yunnan, and Guizhou provinces, which are frequently exposed to severe drought stress. However, low temperature is also found to be the most important environmental factor which can limit the development of pitaya production [5]. Literature has reported that most pitaya cultivars can tolerate $0^{\circ} \mathrm{C}$, which may lead the pitaya fruits and its young buds, shoots, and even some mature branches to death [6]. The lower the temperature with the longer the duration, the more serious the effect on the pitaya yield and quality [7].

Meanwhile, literature has reported that cold stress (classified as chilling $\left(0\right.$ to $\left.15^{\circ} \mathrm{C}\right)$ or freezing $\left(<0^{\circ} \mathrm{C}\right)$ stress) can affect agricultural production [8]. When exposed to low temperature, to adapt to the cold stress, plants require physiological response and cold resistance to survive, which is known as 'cold acclimation' [9]. In the past few years, significant progress in many plants, such as pitaya fruit [7], cassava $[10,11]$, alfalfa [12], petunia seedlings [13], castor seeds [14], rice [15], and grape [16], has been made in understanding the molecular mechanisms under cold stress.

In recent years, literatures reported that the moisture content, chlorophyll content, relative electric conductivity (REC), malonadehyde (MDA) content, soluble sugar content, soluble protein content, free proline content, catalase (CAT) activity, peroxidase (POD) activity, and superoxide dismutase (SOD) activity can be used as the indices to identify the cold resistance [11, 17-21]. Different pitaya varieties have different adaptabilities to the cold resistance, and the cold resistance among different pitaya varieties could be determined by the multi-index comprehensive evaluation [22]. Meanwhile, in the past few years, the comparative proteomic approach has been become a promising tool that is crucial for plants' stress response 
[23-27]. However, to date, our understanding of cold stress mechanisms in pitaya branch is limited.

In this study, the annual branches of three varieties of pitaya (Xianmi (XM), Fulong (FL), and Zihonglong (ZHL)) were selected, and a multivariate statistical method and a comparative proteomic approach were used to investigate the tolerance to cold stress of the annual pitaya branches.

\section{Materials and Methods}

2.1. Plant Material, Growth Condition, and Cold Treatments. The annual branches of three varieties of pitaya (XM, FL, and ZHL) with basically the same cultivation management measures and similar growth potential (approximately $50 \mathrm{~cm}$ length and $10 \mathrm{~cm}$ width without fruits and flowers) were selected from the pitaya demonstration garden of Luodian experimental station of Guizhou Fruit Institute in Dec. 2020. The branches are required to be complete and smooth, with no obvious disease spots on the surface and no obvious mechanical injury or freezing damage. The annual branches of three varieties of pitayas were transferred to a chamber for pretreatment for 1 day at $25^{\circ} \mathrm{C}$. After that, the temperature of the chamber was dropped to $0^{\circ} \mathrm{C}$ with the gradient of $5{ }^{\circ} \mathrm{C} / \mathrm{h}$ for cold treatment with light/dark cycles of $16 / 8 \mathrm{~h}$. The annual branches were exposed to $0^{\circ} \mathrm{C}$ for $0,1,3,5$, and 7 days, respectively, and then frozen at $-80^{\circ} \mathrm{C}$. The branches in the chamber maintained at $25^{\circ} \mathrm{C}$ for 7 days were used as negative controls (CK).

2.2. Physiological Response Analyses. To analyze the physiological responses of the annual pitaya branches under cold stress, the REC, the contents of moisture, chlorophyll, MDA, soluble protein, soluble sugar, and free proline, and the enzyme activities of POD, SOD, and CAT were measured in this study.

2.2.1. Moisture Content Determination. The moisture contents of the annual branches of the three varieties of pitayas were determined according to AOAC official method 934.06 and calculated using formula (1).

$$
\text { Moisture content }(\%)=\frac{\left(m_{a}-m_{b}\right)}{m_{a}} \times 100 \text {. }
$$

In this formula, $m_{\mathrm{a}}$ and $m_{\mathrm{b}}$ are the qualities of samples before and after drying at $70^{\circ} \mathrm{C}$, respectively [28].

2.2.2. Chlorophyll Content Determination. The chlorophyll contents of the annual branches of the three varieties of pitaya were determined by a reported method with some modifications [29]. Each test sample $(50 \mathrm{mg})$ was placed in a $5 \mathrm{~mL}$ precooling mixture solution with $85 \%$ acetone and $85 \%$ ethanol $(\mathrm{v} / \mathrm{v}=1 / 1)$ to be homogenized and incubated in a chamber for $0.5 \mathrm{~h}$ at $25^{\circ} \mathrm{C}$. Then, the supernatant was obtained by centrifuging at $6,500 \mathrm{~g}$ for $15 \mathrm{~min}$. The $\mathrm{OD}_{663}$ and $\mathrm{OD}_{645}$ values of the supernatant were monitored by using a Multiskan Sky 1530 microplate reader (Thermo Scientific, Poland). The contents of chlorophyll a $\left(C_{\mathrm{a}}\right)$, chlorophyll $\mathrm{b}$ $\left(C_{\mathrm{b}}\right)$, and total chlorophyll $\left(C_{\mathrm{t}}\right)$ were calculated using the following equations:

$$
\begin{aligned}
& C_{a}(\mathrm{mg} / \mathrm{L})=0.0127 \mathrm{OD}_{663}-0.00269 \mathrm{OD}_{645} \\
& C_{b}(\mathrm{mg} / \mathrm{L})=0.0229 \mathrm{OD}_{645}-0.00468 \mathrm{OD}_{663} \\
& C_{t}(\mathrm{mg} / \mathrm{L})=C_{a}+C_{b}
\end{aligned}
$$

2.2.3. REC Determination. The REC was determined according to Wang's method [30]. Each test sample (2 g) was placed in $30 \mathrm{~mL}$ distilled water at room temperature for $3 \mathrm{~h}$ to determine the value of electrical conductivity $\left(\mathrm{EC}_{1}\right)$. After that, the test sample was boiled for about $20 \mathrm{~min}$ and then quenched to room temperature to determine the $\mathrm{EC}_{2}$ value. $\mathrm{EC}_{0}$ value was the electrical conductivity value of the distilled water. REC was calculated using the following equation:

$$
\operatorname{REC}(\%)=\frac{\left(\mathrm{EC}_{1}-\mathrm{EC}_{0}\right)}{\left(\mathrm{EC}_{2}-\mathrm{EC}_{0}\right)} \times 100
$$

2.2.4. Determination of the Contents of Soluble Protein, Soluble Sugar, Free Proline, and MDA. The soluble sugar contents were identified according to Solarbio kits (Solarbio, Beijing, China). Coomassie brilliant blue G250 was used to measure the content of soluble protein [31]. The contents of free proline and MDA were measured using the proline and MDA content determination kits (Nanjing Jiancheng Bioengineering Institute, Nanjing, China).

2.2.5. Determination of the Enzyme Activities of CAT, SOD, and POD. The enzyme activities of CAT, SOD, and POD were measured with the corresponding enzyme assay reagent kits (Suzhou Comin Bioengineering Institute, Suzhou, China).

2.2.6. Fuzzy Synthetic Evaluation. The cold resistance abilities of the annual branches of the three varieties of pitaya were evaluated using the fuzzy mathematics method [32]. The positive subordinate function values, such as REC, the contents of MDA, soluble protein, soluble sugar, and free proline, and the activities of SOD, POD, and CAT, were calculated as equation (6); meanwhile, the negative subordinate function values, such as moisture and chlorophyll contents, were calculated as equation (7):

$$
\begin{aligned}
& f\left(X_{i j}\right)=\frac{\left(X_{i j}-X_{\min }\right)}{\left(X_{\max }-X_{\min }\right)}, \\
& f\left(X_{i j}\right)=1-\frac{\left(X_{i j}-X_{\min }\right)}{\left(X_{\max }-X_{\min }\right)},
\end{aligned}
$$

where $f\left(X_{i j}\right)$ is the value of the $i$ pitaya variety of the $j$ item, $X_{i j}$ is the value of the $i$ pitaya variety of the $j$ item, and $X_{\max }$ and $X_{\min }$ are the maximum and minimum values of the $j$ item, respectively. 
2.3. Recovery Growth of Annual Pitaya Branches after Cold Treatment. In order to investigate the recovery growth of the annual pitaya branches after cold treatment at $0^{\circ} \mathrm{C}$ for 7 days, we transplanted the precooling treated annual pitaya branches into the greenhouse with the temperature increased from 0 to $25^{\circ} \mathrm{C}$ by $5^{\circ} \mathrm{C} / \mathrm{h}$, light/dark cycles of $16 / 8 \mathrm{~h}$, and $90 \%$ relative humidity. The survival rate and germination rate were counted after 60 days.

\subsection{Proteomics Analysis}

2.4.1. Protein Extraction and LC-MS/MS Analysis. The annual branches of the three varieties of pitaya, preexposed to $0^{\circ} \mathrm{C}$ for 7 days, were used as the test samples for proteomics analysis. In each experiment, about $1.5 \mathrm{~g}$ fine powder samples were suspended in a $10 \mathrm{~mL}$ precooling acetone solution containing $0.15 \%$ trichloroacetic acid, $10 \%$ polyvinylpyrrolidone, and $0.07 \% \beta$-mercaptoethanol. The solution was stored at $-20^{\circ} \mathrm{C}$ overnight and centrifuged at $8,000 \mathrm{~g}$ and $4^{\circ} \mathrm{C}$ for $30 \mathrm{~min}$. The precipitate was washed using $10 \mathrm{~mL}$ precooled acetone three times and then dissolved in $5 \mathrm{~mL}$ of precooled protein extraction buffer $(40 \mathrm{mM}$ dithiothreitol, $0.1 \mathrm{M} \mathrm{KCl}, 0.7 \mathrm{M}$ sucrose, $50 \mathrm{mM}$ EDTA, and $0.5 \mathrm{M}$ Tris- $\mathrm{HCl}$ $(\mathrm{pH} 7.5)$ ). The protein solution was collected by centrifugation at $12,000 \mathrm{~g}$ and $4^{\circ} \mathrm{C}$ for $15 \mathrm{~min}$. The polypeptide, digested to polypeptide with trypsin at $37^{\circ} \mathrm{C}$ overnight, was dissolved in $50 \mu \mathrm{L}$ of HPLC-grade $\mathrm{H}_{2} \mathrm{O}$ containing $0.1 \%$ formic acid and detected using an AB SCIEX Triple TOF 5600 mass spectrometer (Foster City, CA, USA). The parameters of MS were set according to the manufacturer's recommendations.

2.4.2. Sequence Database Searching and Bioinformatics Analysis. MS/MS spectra (Wiff. files) were analyzed and quantified using the MaxQuant software and searched against the Cactaceae proteome by the reported methods $[33,34]$. The raw data were uploaded in iPorX (http://www. iprox.org) with the accession number of IPX0001296003. The differentially expressed proteins (DEPs) (the expression level $>2$-fold and $p$ value $<0.01)$ at the Gene Ontology (GO) term, named cellular components (CC), biological processes (BP), and molecular function (MF), were calculated. Then, the pathway enrichment of DEPs was identified from the Kyoto Encyclopedia of Genes and Genomes (KEGG) database.

2.5. Statistical Analysis. GraphPad Prism 5 software (GraphPad Software, Inc., San Diego, CA, USA) was used to analyze the significant difference at $p<0.05$.

\section{Results and Discussion}

3.1. Physiological Changes with Cold Treatment. Low temperature can affect the growth and development of many plants, especially originating from tropical and subtropical origins. Due to the time and region of domestication, different varieties of pitaya have different cold resistance. Therefore, in this study, the annual branches of the three varieties of pitaya were selected and the physiological responses on the cold resistance abilities of annual pitaya branches were investigated. The dynamic changes results of moisture and chlorophyll contents in cold stress are listed in Figure 1. Figure 1 shows that compared with the control group (0 day), the moisture content (Figure 1(a)) and chlorophyll content (Figure 1(b)) of the annual branches of the three varieties of pitaya have a tendency to decrease from 1 to 7 days under the cold treatment. In the previous study, the relationship between plant moisture content and cold resistance under low temperature was studied, and the results revealed that the cold resistance was positively correlated with the moisture content [35]. In this study, we found that the cold resistance could decrease the moisture content in annual pitaya branches which are in accord with the previous report [35]. Meanwhile, previous studies showed that the chlorophyll content, which is closely related to photosynthesis, has been proved to be an effective parameter for evaluating plant cold resistance [36-39]. In this study, our results showed that cold stress could significantly decrease the chlorophyll contents in the annual branches of the three varieties of pitaya, which are in accord with the previous reports [40, 41].

Compared with the control group (0 day), the REC (Figure 2(a)) and MDA content (Figure 2(b)) of the annual pitaya branches were increased under cold stress from 0 to 7 days. Overall, with the time extension of cold treatment from 0 to 7 days, the REC and MDA contents of ZHL were consistently lower than those of FL and XM. REC, which was used to research the cytoplasmic membrane damage, is a physiological parameter for evaluating plant cold resistance $[42,43]$. In the previous study, Wang et al. [44] and Li et al. [45] found that the REC of corn seedling and tea leaf could increase under cold stress. In our study, we found that the REC of the annual pitaya branches increases under cold stress, proving that cold stress can increase the membrane permeability of the annual pitaya branches. MDA, an important physiological and biochemical index, can reduce the content of antioxidants to inhibit the activity of cell protective enzymes and accelerate the process of membrane lipid peroxidation [46]. Yin et al. [47] found that the lowtemperature stress had a little effect on the content of MDA in cassava in the early period, but with the extension of stress time, large amounts of MDA were accumulated due to severe peroxidation of membrane lipids. Therefore, determination of MDA content and its dynamics in a plant can reflect the strength of cold resistance of the plant to low-temperature stress. This study results demonstrated that cold stress can increase the MDA content in annual pitaya branches. Similar results were also obtained in the previous studies about cassava [48], maize [49], peach [50], pineapple [51], tomato [52], and rapeseed [53].

Compared with the control group (0 day), the contents of soluble protein (Figure 3(a)), soluble sugar (Figure 3(b)), and free proline (Figure 3(c)) of the annual pitaya branches were enhanced with the extension of the cold stress time from 0 to 7 days. Soluble protein can increase the water content in the cell to reduce the cold injury [54]. In the present study, we demonstrated that the soluble protein 


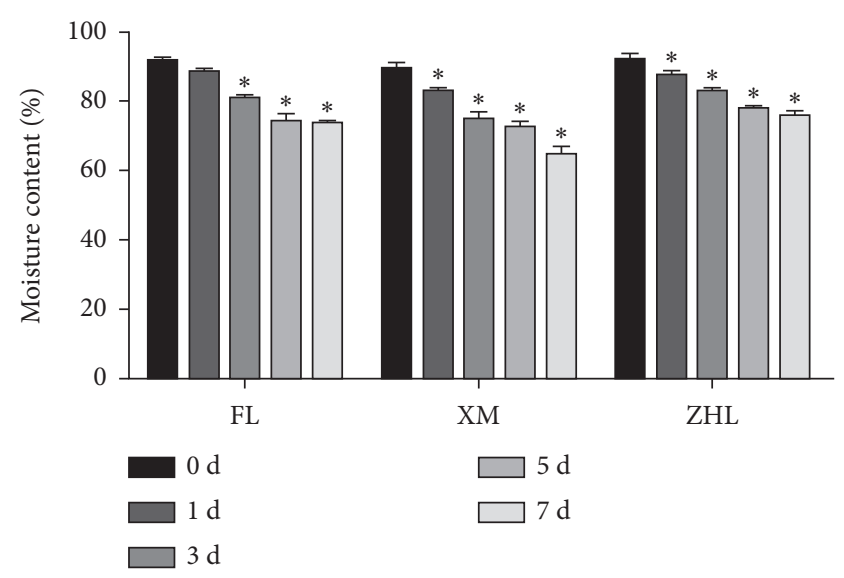

(a)

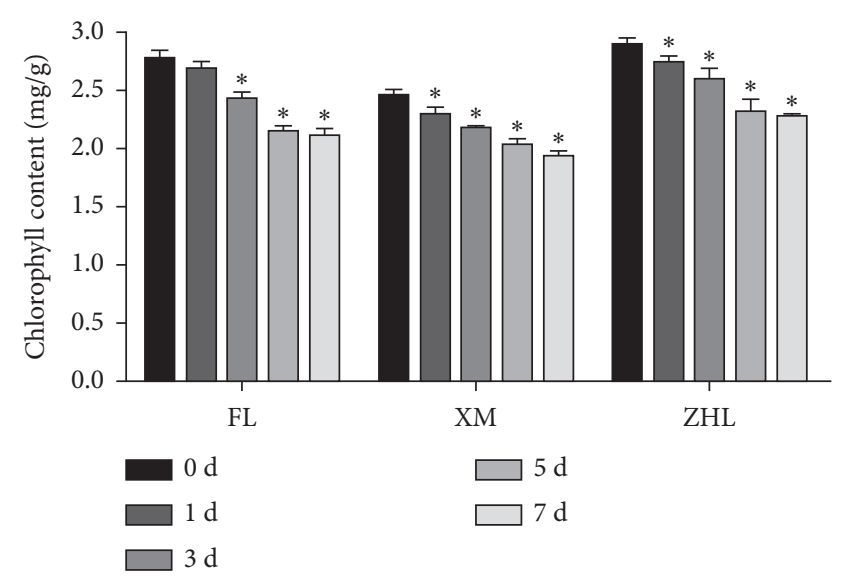

(b)

FIGURE 1: The changes of moisture content (a) and chlorophyll content (b) of the annual branches of the three varieties of pitaya with cold treatment. "*" indicates the changes of moisture content and chlorophyll content with a significant difference at $p<0.05$ compared with the control group.

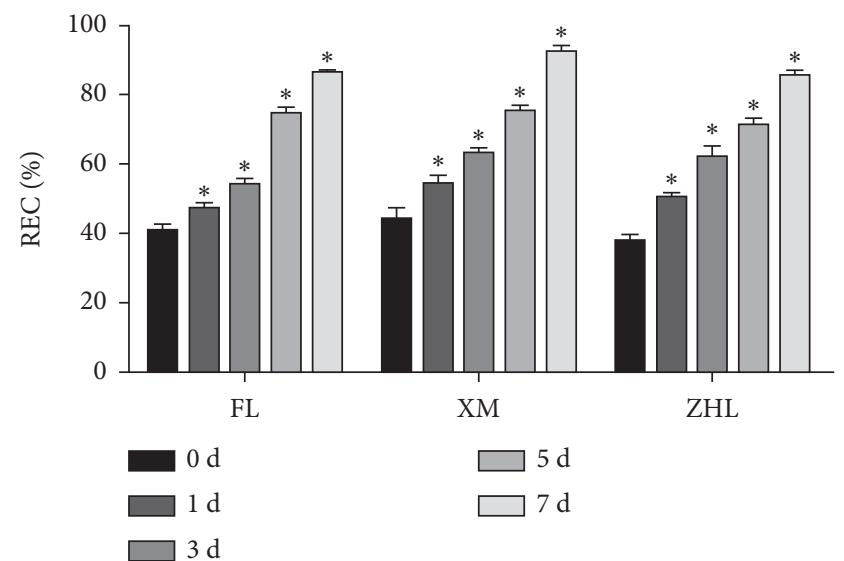

(a)

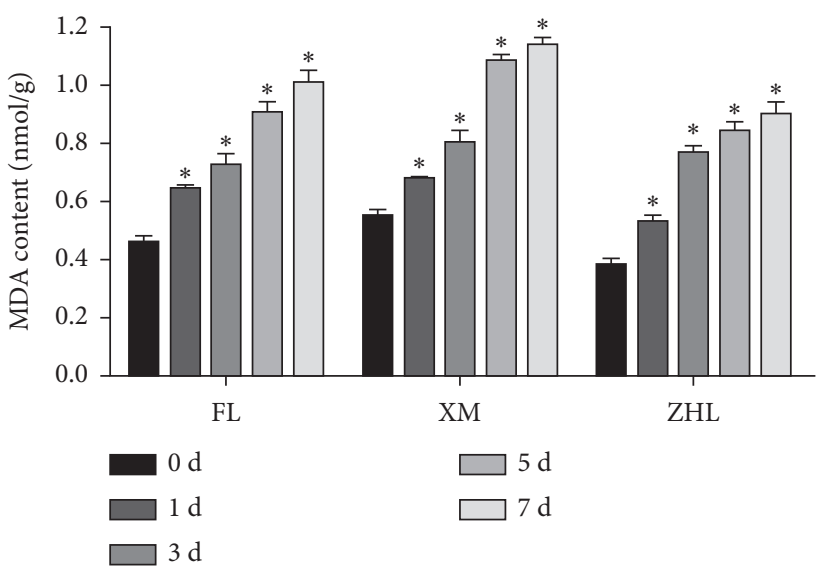

(b)

Figure 2: The changes of REC (a) and MDA content (b) of the annual branches of the three varieties of pitaya with cold treatment. " $*$ " indicates the changes of moisture content and chlorophyll content with a significant difference at $p<0.05$ compared with the control group.

content and cold resistance revealed a positive correlation, and similar results were also obtained by Wallis et al. [55]. Meanwhile, soluble sugar is an important osmotic substance in plant cells, and it can increase the content of intracellular solute. The increase of soluble sugar content is beneficial to the increase of osmotic pressure, thus enhancing the water retention ability of plant cells [55]. This study showed that the soluble sugar content in annual pitaya branches could increase to again be conducive to cold stress.

With the extension time of cold treatment from 0 to 7 days, the antioxidant enzyme activities, including SOD, POD, and CAT, exhibited an increasing trend under cold stress (Figure 4). In the rise trend, the SOD, POD, and CAT activities of ZHL were consistently higher than those of FL and XM. Antioxidant enzymes had an important role in protecting the membrane system for maintaining the normal physiological activities of plants [56]. SOD is a key factor in eliminating reactive oxygen species (ROS) to decrease the ability to minimize oxidative damage under cold stress [57].
Meanwhile, POD can induce the salicylic acid (SA) pathway to promote cell-wall reinforcement, thus activating the systemic acquired resistance (SAR) to cold stress [58, 59]. In addition, CAT can protect plant cells from oxidative damage under cold stress by catalyzing $\mathrm{H}_{2} \mathrm{O}_{2}$ to decompose to water and oxygen [60]. Therefore, our results demonstrated that cold stress may improve cold resistance of plants in the form of antioxidant enzymes.

The cold resistance abilities of the annual branches of the three varieties of pitaya were evaluated using the fuzzy mathematics method, and the results are shown in Table 1. The higher cold resistance abilities have higher value of synthetic evaluation values [61]. Table 1 shows that the synthetic evaluations of cold resistance indicator of the annual branches of XM, FL, and FHL were 0.495, 0.515, and 0.545 , respectively, demonstrating that the cold resistance abilities of the annual branches of the three varieties of pitaya were ranked in the order of $\mathrm{ZHL}>\mathrm{FL}>\mathrm{XM}$. 


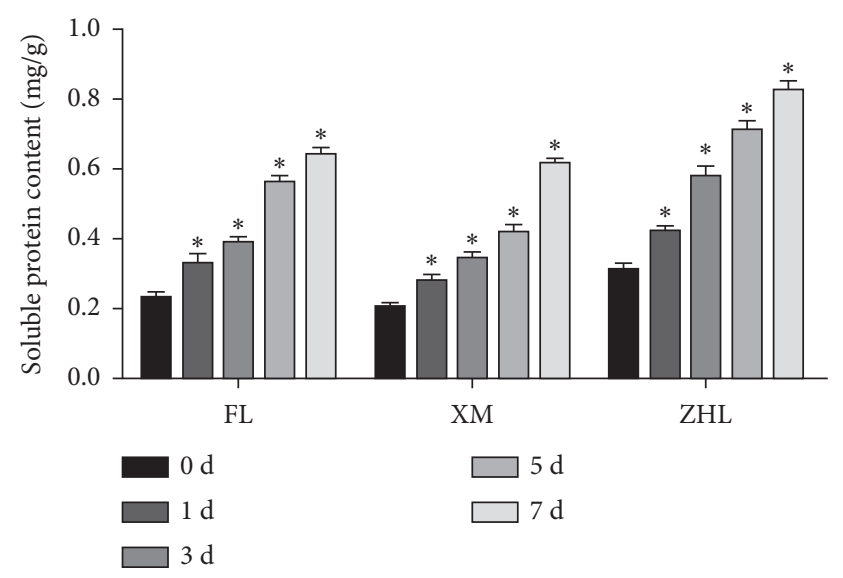

(a)

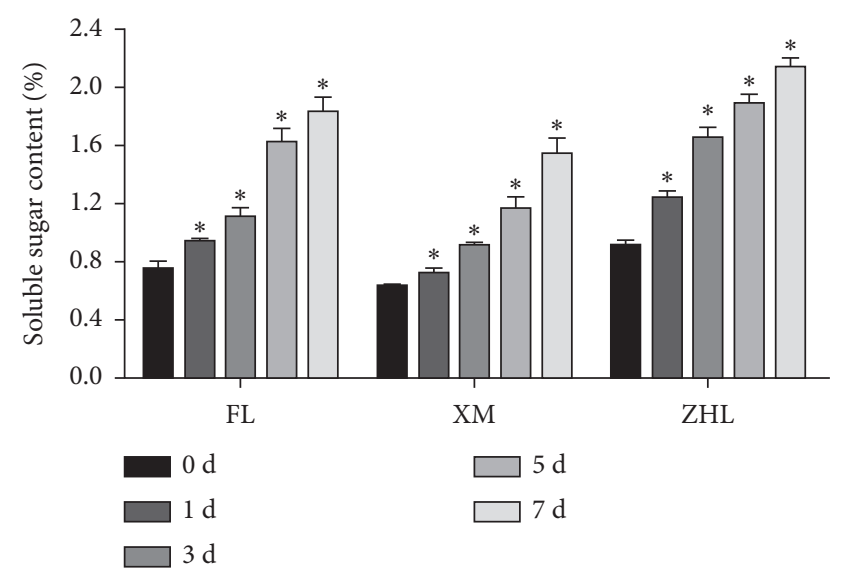

(b)

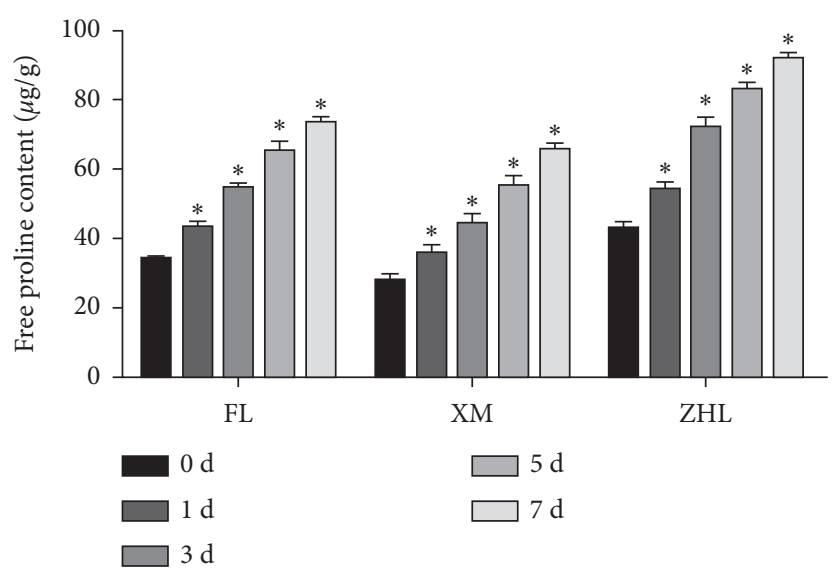

(c)

Figure 3: The changes of soluble protein content (a), soluble sugar content (b), and free proline content (c) of the annual branches of three varieties of pitaya with cold treatment. " $*$ " indicates the changes of soluble protein content, soluble sugar content, and free proline content with a significant difference at $p<0.05$ compared with the control group.

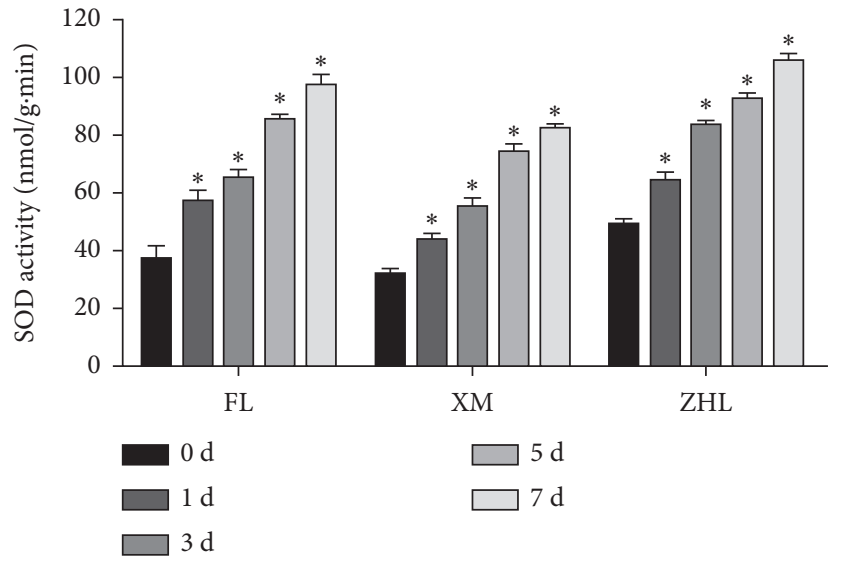

(a)

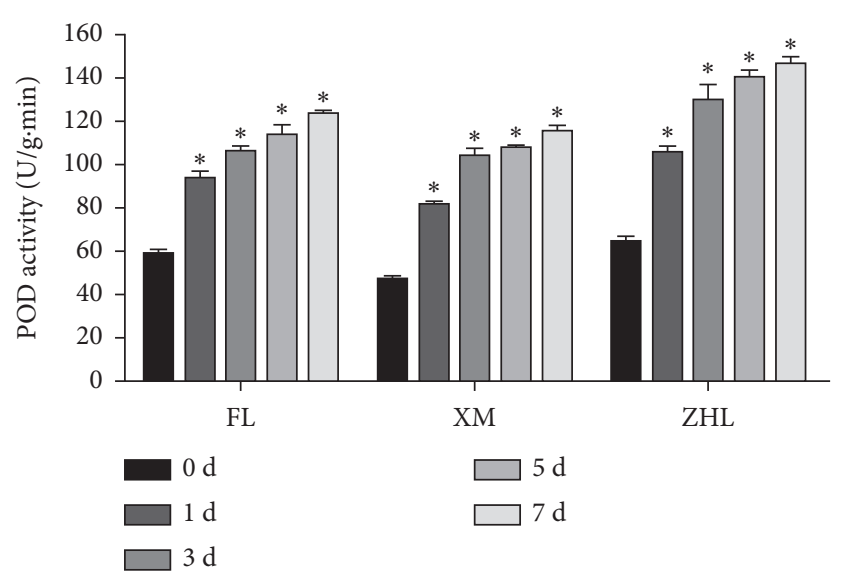

(b)

FIgUre 4: Continued. 


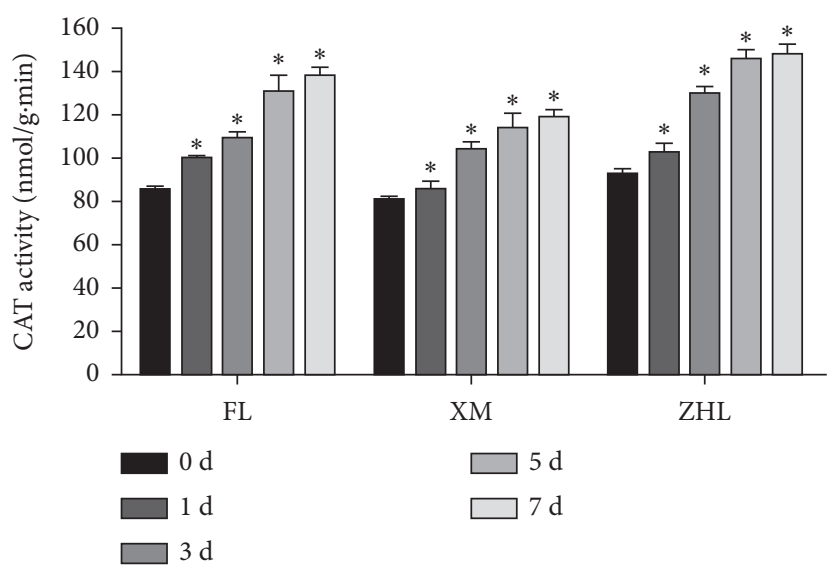

(c)

FIgURE 4: The changes of enzyme activities of SOD (a), POD (b), and CAT (c) of the annual branches of the three varieties of pitaya with cold treatment. " $*$ " indicates the enzyme activity changes of SOD, POD, and CAT with a significant difference at $p<0.05$ compared with the control group.

3.2. Recovery Growth of Annual Pitaya Branches after Cold Treatment. After 60 days of recovery growth, the results, as shown in Table 2, showed that ZHL had the best survival rate $(45.25 \%)$ and germination rate $(39.16 \%)$, followed by FL (35.16\% and $31.58 \%$, respectively) and XM (26.62\% and $21.49 \%$, respectively), showing that the cold resistance abilities of the annual branches of the three varieties of pitaya were in the order of $\mathrm{ZHL}>\mathrm{FL}>\mathrm{XM}$.

3.3. Label-Free Proteomics Analysis. The proteomics technique was used to analyze the cold stress responses of the annual branches of the three varieties of pitaya. A total of 2798 proteins were identified in the annual branches of the three varieties of pitaya, and the results are listed in Table S1, of which 1900, 2099, and 2023 proteins were identified in the annual branches of ZHL, FL, and XM, respectively. Meanwhile, the box plot (Figure 5(a)) and normal distribution (Figure 5(b)) of the protein expression of the three varieties of pitaya indicated that compared with FL and XM, ZHL had the highest protein expression abundance.

As shown in Figure 6(a) and Table S1, the numbers of identified proteins of ZHL vs. XM showing up- and downregulation were 699 and 450, respectively. Figure 6(b) and Table S1 show that the up- and downregulated proteins of ZHL vs. FL were 494 and 784, respectively. Figure 6(c) and Table S1 also show that the up- and downregulated proteins of FL vs. XM were 492 and 390, respectively. Meanwhile, to clarify the cold resistance ability-related proteins in the annual branches of the three varieties of pitaya, the numbers of in turn up$($ mode $=1)$ and downregulated $(\operatorname{mode}=-1)$ expression proteins were also investigated, and the results are listed in Figure 7 and Table S2. As shown in Figure 7 and Table S2, the numbers of in turn up- and downregulated expression proteins in XM, FL, and ZHL were 479 and 261, respectively.

The functions of the in turn up- and downregulated expression proteins were annotated by GO analysis and further classified into the categories of $\mathrm{MF}, \mathrm{CC}$, and $\mathrm{BP}$. GO term enrichment analysis of the in turn up- and downregulated expression proteins revealed that main CC involved ribosome (GO:0005840), cytoplasm (GO:0005737), membrane (GO: 0016020), mitochondrion (GO:0005739), and chloroplast (GO: 0009507); main BP involved translation (GO:0006412), carbohydrate metabolism (GO:0005975), small-molecule metabolism (GO:0044281), response to stress (GO:0006950), and transport (GO:0006810); and main MF involved structural molecule activity (GO:0005198), lyase activity (GO:0016829), rRNA binding (GO:0019843), oxidoreductase activity (GO: 0016491), and ligase activity (GO:0016874). Meanwhile, KEGG analysis results, shown in Table S3, showed that the in turn upand downregulated expression proteins identified in XM, FL, and ZHL were mainly related to autophagy (path:ko04138), carbon fixation pathways in prokaryotes (path:ko00720), fluid shear stress and atherosclerosis (path:ko05418), Epstein-Barr virus infection (path:ko05169), and biosynthesis of amino acids (path:ko01230). It is worth noting that the pathway with the highest enrichment was autophagy (path:ko04138). Autophagy, a major process of protein degradation, can recycle nutrient contents to remove the damaged proteins when exposed to the environmental stress conditions [62, 63]. Recent studies had divulged that autophagy is extremely important in environmental stress and plant development [64-69]. Therefore, our results demonstrated that autophagy may play a key role in response to cold stress in annual pitaya branches, and we concluded that the pitaya branches could be improve tolerance to cold stress by modulating autophagy to clean up the damaged cellular structures caused by cold stress conditions for recycling of nutrients. 


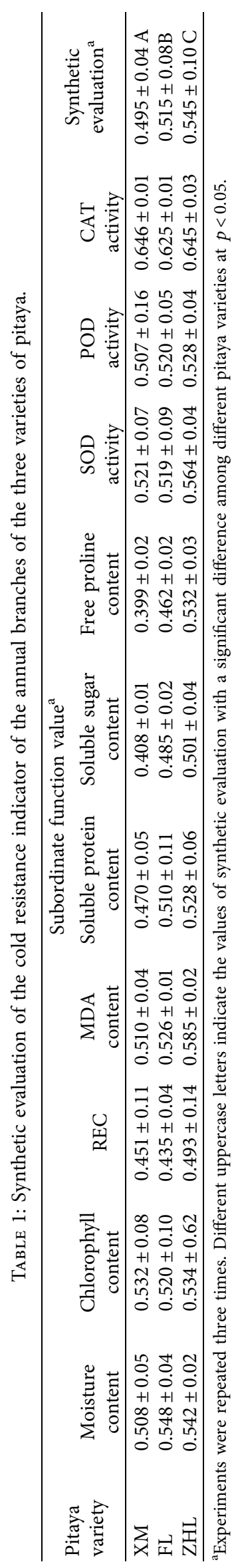


TABle 2: The survival rate and germination rate of the annual branches of the three varieties of pitaya.

\begin{tabular}{lcr}
\hline Pitaya varieties & Survival rate $(\%)^{\mathrm{a}}$ & ${\text { Germination rate }(\%)^{\mathrm{a}}}^{\mathrm{a}}$ \\
ZHL & $45.25 \pm 3.65 \mathrm{~A}$ & $39.16 \pm 2.65 \mathrm{~A}$ \\
FL & $35.16 \pm 2.95 \mathrm{~B}$ & $31.58 \pm 4.16 \mathrm{~B}$ \\
XM & $26.62 \pm 5.26 \mathrm{C}$ & $21.49 \pm 1.98 \mathrm{C}$ \\
\hline
\end{tabular}

${ }^{a}$ Experiments were repeated three times. Different uppercase letters indicate the values of survival rate and germination rate with a significant difference among different pitaya varieties at $p<0.05$.

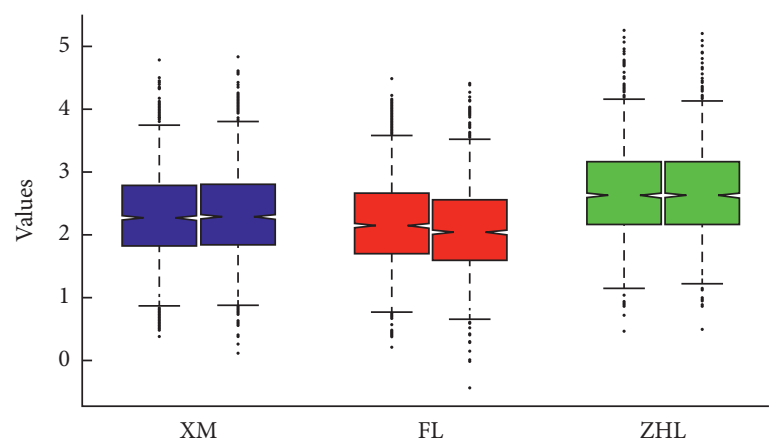

(a)

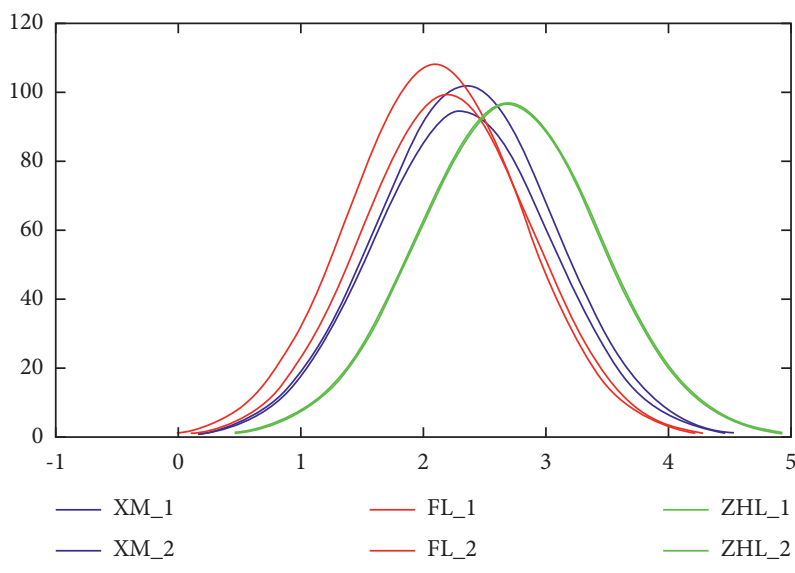

(b)

FIGURE 5: The box plot (a) and normal distribution (b) of the protein expression of the annual branches of the three varieties of pitaya.

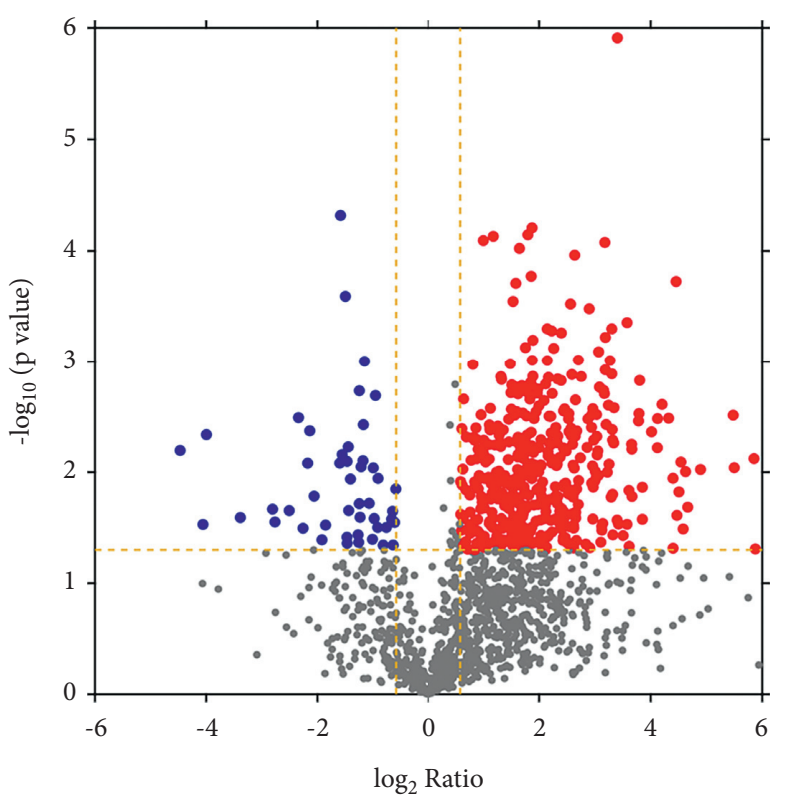

(a)

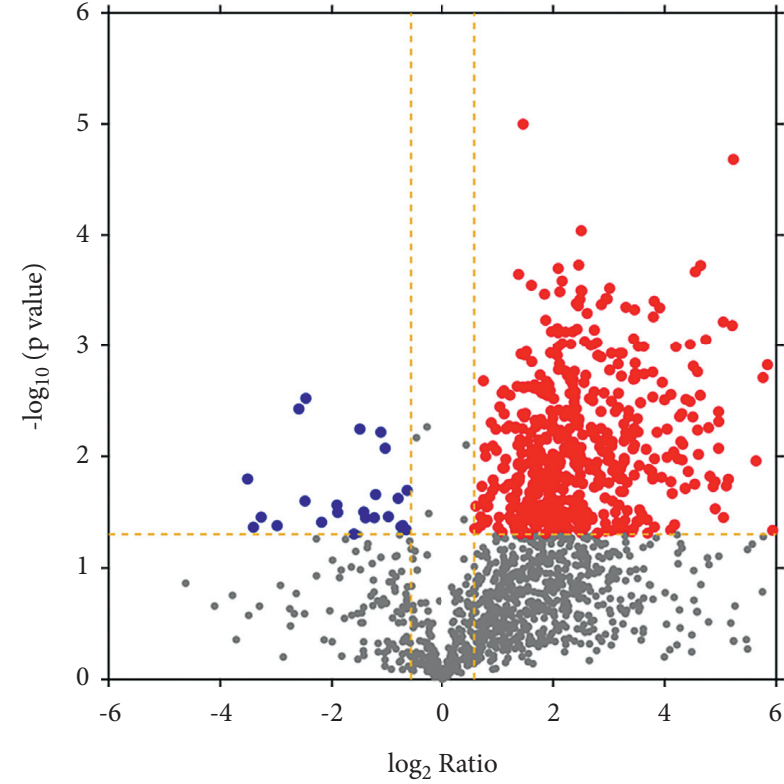

(b)

Figure 6: Continued. 


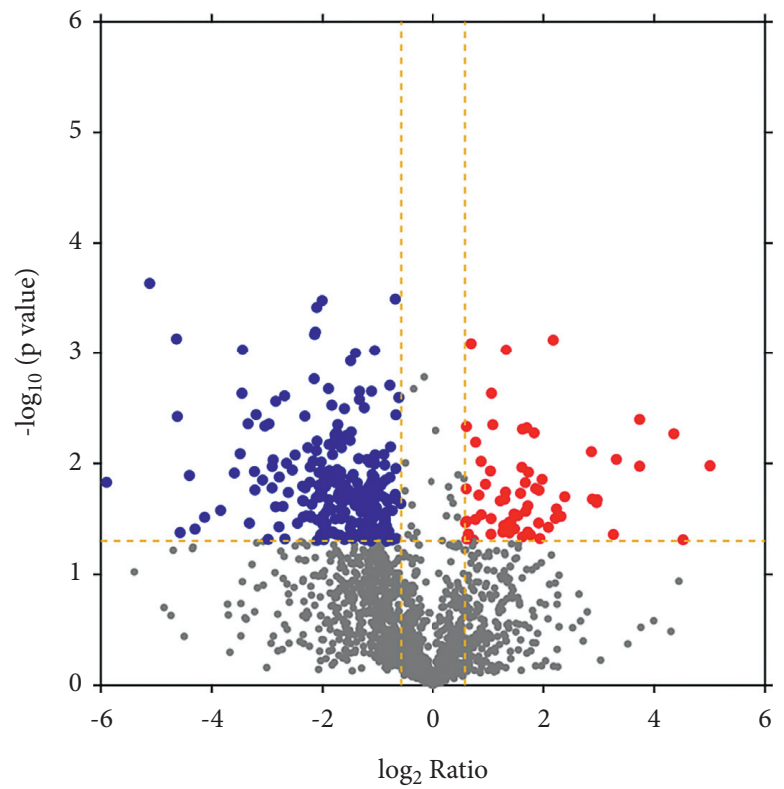

(c)

Figure 6: Volcano plot of the relative protein abundance changes in the annual branches of the three varieties of pitaya. (a) ZHL vs. XM, (b) ZHL vs. FL, and (c) FL vs. XM. The green and red dots are the up- and downregulated DEPs, respectively.

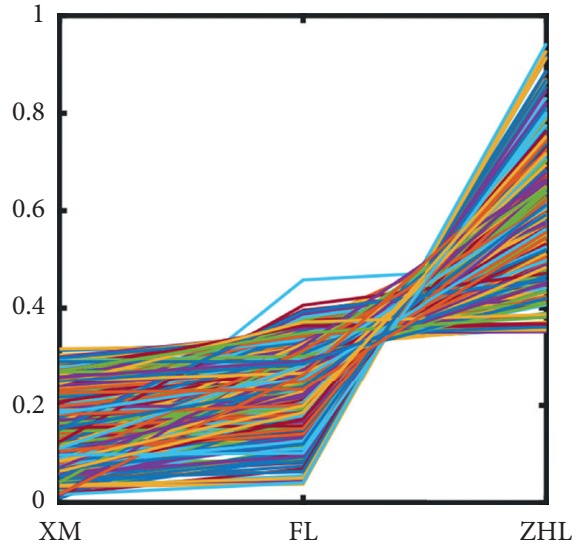

(a)

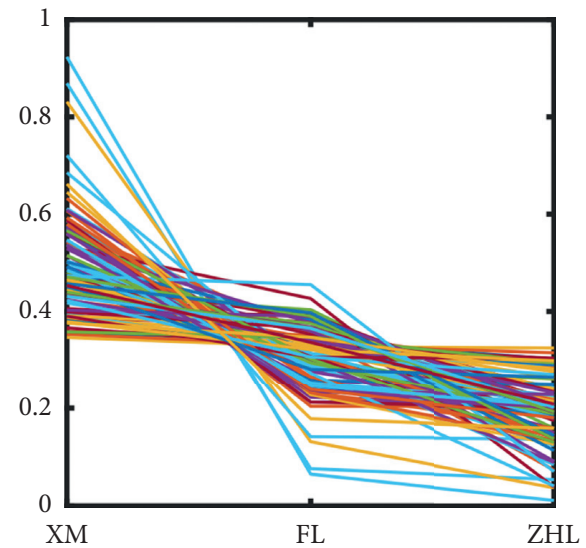

(b)

Figure 7: The in turn up- (a) and downregulated (b) expression proteins in the annual branches of the three varieties of pitaya.

\section{Conclusions}

In conclusion, the physiological and proteome dynamic changes in the annual branches of the three varieties of pitaya were investigated using a multivariate statistical method and a comparative proteomic approach, respectively. Physiological response results showed that the contents of moisture and chlorophyll decreased, in contrast with the REC and the contents of MDA, soluble protein, soluble sugar, and free proline increased, and the enzyme activities of SOD, POD, and CAT enhanced in annual pitaya branches under cold stress. Meanwhile, proteomic analysis results concluded that the pitaya branches could improve tolerance to cold stress by modulating autophagy. In addition, the physiological and proteome dynamic changes results demonstrated that the cold resistance of the annual branches of the three varieties of pitaya should be in the order of FHL $>$ FL $>$ XM which are in accord with the cold resistance ability in agricultural production under the natural environment condition. Our results provide a better understanding of how the annual pitaya branches respond and survive under low temperatures.

\section{Data Availability}

The datasets used and analyzed during the current study are available from the corresponding author on reasonable request. 


\section{Conflicts of Interest}

The authors declare no conflicts of interest.

\section{Authors' Contributions}

Junliang Zhou and Lijuan Wang contributed equally to this work.

\section{Acknowledgments}

This research was funded by the National Natural Science Foundation of China, grant no. 31560547; Guizhou Provincial Talent Base Project, grant no. [2018]3, and Special Funds for Innovation Capacity Building of Research Institutions, grant no. [2019]4002.

\section{Supplementary Materials}

Table S1: list of identified proteins in the annual branches of $\mathrm{XM}, \mathrm{FL}$, and FHL; Table S2: the in turn up- and downregulated expression proteins in the annual branches of XM, FL, and FHL; Table S3: the KEGG analysis results of the in turn up- and downregulated expression proteins in the annual branches of XM, FL, and FHL. (Supplementary Materials)

\section{References}

[1] K. Mahattanatawee, J. A. Manthey, G. Luzio, S. T. Talcott, K. Goodner, and E. A. Baldwin, "Total antioxidant activity and fiber content of select Florida-grown tropical fruits," Journal of Agricultural and Food Chemistry, vol. 54, no. 19, pp. 7355-7363, 2006.

[2] N. Sengkhamparn, N. Chanshotikul, C. Assawajitpukdee, and T. Khamjae, "Effects of blanching and drying on fiber rich powder from pitaya (Hylocereus undatus) peel," International Food Research Journal, vol. 20, no. 4, pp. 1595-1600, 2013.

[3] B. Rodriguez-Jimenez, J. Dominguez-Ortega, A. Ledesma, B. Cava-Sumner, and C. Kindelan-Recarte, "Generalized urticaria due to yellow pitahaya (Selenicereus megalanthus)," Journal of Investigational Allergology and Clinical Immunology, vol. 24, no. 2, pp. 124-125, 2014.

[4] G. Jiménez, G. Gómez, A. M. Pérez, and A. Blanco-Metzler, "Estimation of glycaemic index of peach palm (Bactris gasipaes) cooked fruits and chips, and pitahaya (Hylocereus spp.) pulp," Archivos Latinoamericanos de Nutricion, vol. 62, no. 3, pp. 242-248, 2012.

[5] R. J. Deng, J. X. Fan, Y. Q. Wang, J. F. Jin, and T. Liu, "Semilethal temperature of Pitaya under low temperature stress and evaluation on their cold resistance," Plant Physiology Journal, vol. 50, no. 11, pp. 1742-1748, 2014.

[6] R. J. Deng, J. X. Fan, B. Wang, and Y. Q. Cai, "Preliminary study on determination of chilling-resistance in pitaya (Hylocereus spp.)," Plant Physiology Communications, vol. 45, no. 10, pp. 1023-1026, 2009.

[7] J. Corrales-García and E. Canche-Canche, "Physical and physiological changes in low-temperature-stored pitahaya fruit (Hylocereus undatus)," Journal of the Professional Association for Cactus Development, vol. 10, pp. 108-119, 2008.

[8] R.-j. Feng, L.-1. Zhang, J.-y. Wang et al., "Proteomic analysis of cold stress responses in banana leaves," Journal of the
American Society for Horticultural Science, vol. 140, no. 3, pp. 214-222, 2015.

[9] M. F. Thomashow, "Plant cold acclimation: freezing tolerance genes and regulatory mechanisms," Annual Review of Plant Physiology and Plant Molecular Biology, vol. 50, no. 1, pp. 571-599, 1999.

[10] W. Zhang, T. Yi, Y. Wu, and Y. Song, "Research progress of cold resistance mechanism of cassava," Agricultural Science \& Technology, vol. 18, no. 9, pp. 1607-1614, 2017.

[11] F. An, G. Li, Q. X. Li et al., "The comparatively proteomic analysis in response to cold stress in cassava plantlets," Plant Molecular Biology Reporter, vol. 34, no. 6, pp. 1095-1110, 2016.

[12] J. Chen, G. Han, C. Shang et al., "Proteomic analyses reveal differences in cold acclimation mechanisms in freezing-tolerant and freezing-sensitive cultivars of alfalfa," Frontiers of Plant Science, vol. 6, p. 105, 2015.

[13] W. Zhang, H. Zhang, L. Ning, B. Li, and M. Bao, "Quantitative proteomic analysis provides novel insights into cold stress responses in petunia seedlings," Frontiers of Plant Science, vol. 7, p. 136, 2016.

[14] X. Wang, M. Li, X. M. Liu, L. Zhang, Q. Duan, and J. Zhang, "Quantitative proteomic analysis of castor (Ricinus communis L.) seeds during early imbibition provided novel insights into cold stress response," International Journal of Molecular Sciences, vol. 20, no. 2, p. 355, 2019.

[15] K. A. Neilson, M. Mariani, and P. A. Haynes, "Quantitative proteomic analysis of cold-responsive proteins in rice," Proteomics, vol. 11, no. 9, pp. 1696-1706, 2011.

[16] Z. M. Wu, X. Z. Yuan, H. Li et al., "Heat acclimation reduces postharvest loss of table grapes during cold storage - analysis of possible mechanisms involved through a proteomic approach," Postharvest Biology and Technology, vol. 105, pp. 26-33, 2015.

[17] G. Wang, J. Wang, X. Xue, L. U. Chao, and P. Nie, "Research progress and identification method of apple stress resistance," Agricultural Science \& Technology, vol. 18, no. 10, pp. 14131416, 2013.

[18] B. Q. Zhang, L. T. Yang, and Y. R. Li, "Physiological and biochemical characteristics related to cold resistance in sugarcane," Sugar Tech, vol. 17, pp. 49-58, 2015.

[19] X. Li, J. P. Wei, E. R. Scott et al., "Exogenous melatonin alleviates cold stress by promoting antioxidant defense and redox homeostasis in Camellia sinensis L," Molecules, vol. 23, no. 1, p. $165,2018$.

[20] X. F. Zhang, W. Shen, and S. Gurunathan, "Biologically synthesized gold nanoparticles ameliorate cold and heat stress-induced oxidative stress in Escherichia coli," Molecules, vol. 21, no. 6, p. 731, 2016.

[21] Y. Z. Yang, G. Chen, F. R. Peng et al., "Differences in water and osmoregulation substance contents in Toona sinensis from different provenances under low temperature stress and their correlation to cold tolerance," Journal of Plant Resources and Environment, vol. 23, no. 4, pp. 47-54, 2014.

[22] G. Zhang, J. Bai, M. Xi et al., "Soil quality assessment of coastal wetlands in the Yellow River Delta of China based on the minimum data set," Ecological Indicators, vol. 66, pp. 458466, 2016.

[23] K. K. Meena, A. M. Sorty, U. M. Bitla et al., "Abiotic stress responses and microbe-mediated mitigation in plants: the omics strategies," Frontiers of Plant Science, vol. 8, p. 172, 2017.

[24] M. J. Li, D. X. Li, F. J. Feng et al., "Proteomic analysis reveals dynamic regulation of fruit development and sugar and acid 
accumulation in apple," Journal of Experimental Botany, vol. 67, no. 17, pp. 5145-5157, 2016.

[25] S. L. Xu, R. J. Chalkley, J. C. Maynard et al., "Proteomic analysis reveals O-GlcNAc modification on proteins with key regulatory functions in Arabidopsis," Proceedings of the National Academy of Sciences USA, vol. 114, no. 8, pp. E1536-E1543, 2017.

[26] A. Aroca, J. M. Benito, C. Gotor, and L. C. Romero, "Persulfidation proteome reveals the regulation of protein function by hydrogen sulfide in diverse biological processes in Arabidopsis," Journal of Experimental Botany, vol. 68, no. 17, pp. 4915-4927, 2017.

[27] Z. Y. Shan, X. L. Luo, M. G. Wei et al., "Physiological and proteomic analysis on long-term drought resistance of cassava (Manihot esculenta Crantz)," Scientific Reports, vol. 8, p. 17982, 2018.

[28] M. Fouskaki, K. Karametsi, and N. A. Chaniotakis, "Method for the determination of water content in sultana raisins using a water activity probe," Food Chemistry, vol. 82, no. 1, pp. 133-137, 2003.

[29] J. Zhao, J. J. Zhou, Y. Y. Wang, J. W. Gu, and X. Z. Xie, "Positive regulation of phytochrome $\mathrm{B}$ on chlorophyll biosynthesis and chloroplast development in rice," Rice Science, vol. 20, no. 4, pp. 243-248, 2013.

[30] Y. X. Wang, Y. Hu, B. H. Chen et al., "Physiological mechanisms of resistance to cold stress associated with 10 elite apple rootstocks," Journal of Integrative Agriculture, vol. 17, no. 4, pp. 857-866, 2018.

[31] J. J. Sedmak and S. E. Grossberg, "A rapid, sensitive, and versatile assay for protein using Coomassie brilliant blue G250," Analytical Biochemistry, vol. 79, no. 1-2, pp. 544-552, 1977.

[32] N. Wang, M. L. Yuan, and F. Yang, "Physiological changes and cold tolerance of three camphor species during natural winter temperature fluctuations," Journal of Northwest A \& $F$ University, vol. 21, pp. 7-16, 2014.

[33] J. Cox, N. Neuhauser, A. Michalski et al., "Andromeda: a peptide search engine integrated into the MaxQuant environment," Journal of Proteome Research, vol. 10, no. 4, pp. 1794-1805, 2011.

[34] L. Yu, W. L. Wang, S. Zeng et al., "Label-free quantitative proteomics analysis of Cytosinpeptidemycin responses in southern rice black-streaked dwarf virus-infected rice," Pesticide Biochemistry and Physiology, vol. 147, pp. 20-26, 2018.

[35] W. Yamori, K. Hikosaka, and D. A. Way, "Temperature response of photosynthesis in C3, C4, and CAM plants: temperature acclimation and temperature adaptation," Photosynthesis Research, vol. 119, pp. 101-117, 2014.

[36] E. Ghasemie, M. Kazempour, and F. Padasht, "Isolation and identification of Xathomonas oryzae pv. oryzae the causal agent of bacterial blight of rice in Iran," Journal of Plant Protection Research, vol. 48, no. 1, pp. 53-62, 2008.

[37] B. Ehlert and D. K. Hincha, "Chlorophyll fluorescence imaging accurately quantifies freezing damage and cold acclimation responses in Arabidopsis leaves," Plant Methods, vol. 4, p. 12, 2008.

[38] F. Rizza, D. Pagani, A. Stanca, and L. Cattivelli, "Use of chlorophyll fluorescence to evaluate the cold acclimation and freezing tolerance of winter and spring oats," Plant Breeding, vol. 120, no. 5, pp. 389-396, 2001.

[39] A. Aghaee, F. Moradi, H. Zare-Maivan et al., "Physiological responses of two rice (Oryza sativa L.) genotypes to chilling stress at seedling stage," African Journal of Biotechnology, vol. 10, no. 39, pp. 7617-7621, 2011.
[40] C. J. Zhang, J. X. Liu, Y. Y. Zhang et al., "Overexpression of SIGMEs leads to ascorbate accumulation with enhanced oxidative stress, cold, and salt tolerance in tomato," Plant Cell Reports, vol. 30, pp. 389-398, 2011.

[41] W. Y. Liu, K. M. Yu, T. F. He, D. X. Zhang, and J. X. Liu, "The low temperature induced physiological responses of Avena nuda L., a cold-tolerant plant species," Science World Journal, vol. 2013, pp. 1-7, Article ID 658793, 2013.

[42] L. J. Chen, H. Z. Xiang, Y. Miao et al., "An overview of cold resistance in plants," Journal of Agronomy and Crop Science, vol. 200, no. 4, pp. 237-245, 2014.

[43] R. E. Blankenship, Molecular Mechanisms of Photosynthesis, pp. 149-151, Blackwell Sci, Oxford, UK, 2002.

[44] R. Wang, F. M. Ma, C. F. Li, S. Y. Chen, and J. Hou, "Effect of low temperature stress on proline, malondialdehyde contents and electric conductivity of maize seedling," Journal of Northwest A \& F University, vol. 39, pp. 20-23, 2008.

[45] Y. Y. Li, L. Pang, Q. W. Chen, Y. Q. Zhou, and C. J. Jiang, "The influence of physiological characteristics of tea tree leaf on low temperature stress," Journal of Northwest A \& F University, vol. 40, pp. 134-145, 2012.

[46] W. Zhang, T. Yi, Y. Wu, and Y. Song, "Research progress of cold resistance mechanism of cassava," Agricultural Science \& Technology, vol. 18, no. 9, pp. 1607-1614, 2017.

[47] C. X. Yin, R. X. Yao, and A. M. Qiao, “The response to cold stress and evaluation of cold resistance of five cassava varieties," Guangdong Agricultural Science, vol. 39, pp. 30-33, 2012.

[48] Q. F. Huang, X. L. Luo, C. L. Wang, X. L. Lai, and C. L. Wei, "Effects of low temperature stress on physiological and biochemical characteristics of cassava seedling," Chinese Agricultural Science Bulletin, vol. 26, no. 17, pp. 172-177, 2010.

[49] M. P. Zunino and J. A. Zygadlo, "Effect of monoterpenes on lipid oxidation in maize," Planta, vol. 219, pp. 303-309, 2004.

[50] L. Zhou, K. Liao, L. Wang, Z. Xu, and W. Y. Yang, "Study on resistance to coldness of Prunus divaricate," Journal of Xinjiang Agricultural University, vol. 29, no. 1, pp. 47-50, 2006.

[51] X. H. Lu, G. M. Sun, and C. H. Ye, "Changes of membrane permeability, malondialdehyde and chlorophyll content in pineapple seedlings under low temperature stress," Journal of Anhui Agricultural University, vol. 38, no. 16, pp. 8374-8375, 2010.

[52] J. Zhang and W. M. Zhu, "Effects of chilling stress on contents of chlorophyll and malondialdehyde in tomato seedlings," Acta Agriculture Shanghai, vol. 28, no. 3, pp. 74-77, 2012.

[53] S. L. Wang, H. Y. Huang, J. Tang, R. Q. Wang, and X. Q. Wang, "Effects of low temperature stress on the content of malondialdehyde in rape seedlings," Hubei Agricultural Sciences, vol. 51, no. 20, pp. 4467-4469, 2012.

[54] Y. Gao, X. H. Qi, J. H. Yang, and M. F. Zhang, "The response mechanism of cold stress in higher plants," Northern Horticulture, vol. 10, pp. 58-61, 2007.

[55] J. G. Wallis, H. Wang, and D. J. Guerra, "Expression of a synthetic antifreeze protein in potato reduces electrolyte release at freezing temperatures," Plant Molecular Biology, vol. 35 , pp. 323-330, 1997.

[56] T. Gechev, H. Willekens, M. Van Montagu et al., "Different responses of tobacco antioxidant enzymes to light and chilling stress," Journal of Plant Physiology, vol. 160, no. 5, pp. 509-515, 2003.

[57] M. Hermes-Lima, "Oxygen in biology and biochemistry: role of free radicals," in Functional Metabolism: Regulation and Adaptation, K. B. Storey, Ed., pp. 319-368, John Wiley \& Sons Inc., Hoboken, NJ, USA, 2004. 
[58] J. C. M. S. Moura, C. A. V. Bonine, J. De Oliveira Fernandes Viana, M. C. Dornelas, and P. Mazzafera, "Abiotic and biotic stresses and changes in the lignin content and composition in plants," Journal of Integrative Plant Biology, vol. 52, no. 4, pp. 360-376, 2010.

[59] R. L. Nicholson and R. Hammerschmidt, "Phenolic compounds and their role in disease resistance," Annual Review of Phytopathology, vol. 30, pp. 369-389, 1992.

[60] Y. Y. Du, P. C. Wang, J. Chen, and C. P. Song, "Comprehensive functional analysis of the catalase gene family in Arabidopsis thaliana," Journal of Integrative Plant Biology, vol. 50, no. 10, pp. 1318-1326, 2008.

[61] G. F. Xu, C. Y. Zhang, and Z. X. Xiang, "Comprehensive evaluation of cold resistance on four Lysimachia plants by subordinate function values analysis," Journal of Northwest Forestry University, vol. 24, no. 3, pp. 24-26, 2009.

[62] K. Yoshimoto, Y. Takano, and Y. Sakai, "Autophagy in plants and phytopathogens," FEBS Letters, vol. 584, no. 7, pp. 1350-1358, 2010.

[63] Y. F. Zhai, M. Guo, H. Wang et al., "Autophagy, a conserved mechanism for protein degradation, responds to heat, and other abiotic stresses in Capsicum annuum L," Frontiers of Plant Science, vol. 7, p. 131, 2016.

[64] S. Slavikova, S. Ufaz, T. Avin-Wittenberg, H. Levanony, and G. Galili, "An autophagy-associated Atg8 protein is involved in the responses of Arabidopsis seedlings to hormonal controls and abiotic stresses," Journal of Experimental Botany, vol. 59, no. 14, pp. 4029-4043, 2008.

[65] Y. M. Liu, Y. Xiong, and D. C. Bassham, "Autophagy is required for tolerance of drought and salt stress in plants," Autophagy, vol. 5, pp. 954-963, 2009.

[66] J. H. Shin, K. Yoshimoto, Y. Ohsumi, J. S. Jeon, and G. An, "OsATG10b, an autophagosome component, is needed for cell survival against oxidative stresses in rice," Molecules and Cells, vol. 27, pp. 67-74, 2009.

[67] D. Kuzuoglu-Ozturk, O. C. Yalcinkaya, B. A. Akpinar et al., "Autophagy-related gene, TdAtg8, in wild emmer wheat plays a role in drought and osmotic stress response," Planta, vol. 236, pp. 1081-1092, 2012.

[68] D. Pei, W. Zhang, H. Sun et al., "Identification of autophagyrelated genes ATG4 and ATG8 from wheat (Triticum aesti$v u m$ L.) and profiling of their expression patterns responding to biotic and abiotic stresses," Plant Cell Reports, vol. 33, pp. 1697-1710, 2014.

[69] L. Chen, B. Liao, H. Qi et al., "Autophagy contributes to regulation of the hypoxia response during submergence in Arabidopsis thaliana," Autophagy, vol. 11, no. 12, pp. 2233-2246, 2015. 